\title{
Solar Energy Potential and Future Prospects in Afar Region, Ethiopia
}

\author{
Anshebo Getachew Alemu ${ }^{1, *}$, Teketel Alemu \\ ${ }^{1}$ Department of Physics, Samara University, Faculty of Natural and Computational Science, Samara, Ethiopia \\ ${ }^{2}$ Department of Chemical Engineering, Adama University of Science and Technology, Adama, Ethiopia
}

Email address:

agetachew2013alemu@yahoo.com (A. G. Alemu), teketela20@gmail.com (T. Alemu)

${ }^{*}$ Corresponding author

\section{To cite this article:}

Anshebo Getachew Alemu, Teketel Alemu. Solar Energy Potential and Future Prospects in Afar Region, Ethiopia. American Journal of Modern Energy. Vol. 7, No. 2, 2021, pp. 22-26. doi: 10.11648/j.ajme.20210702.12

Received: December 19, 2020; Accepted: January 11, 2021; Published: May 26, 2021

\begin{abstract}
The objective of the study is to provide scientific information of the solar potential of Afar region, for photovoltaic (PV) solar energy industry sectors. The afar region being exceptional solar potential with high average solar radiation flux $239.9 \mathrm{~W} / \mathrm{m}^{2}\left(105.4 \%\right.$ of average photon energy surface area of Ethiopia), and average annual solar density of $2.102 \mathrm{MW} \cdot \mathrm{h} / \mathrm{m}^{2}$ ( $105.5 \%$ of the average yearly solar density of Ethiopia). This finding requests the photovoltaic system as an alternative principal energy resource to substitute the present energy system in afar region. These comprehensive indication of the solar energy marketplace in Afar region, Ethiopia, key visions into its governing framework, energy sector, of photovoltaic (PV) industry segments. Therefore, the photovoltaic energy system has the best opportunity for basic energy application in the pastoral community for daily life consumption, such as solar lighting, for solar cooker, small devices and for air conditioning. These studies show that the Afar region gifted with significantly high monthly average daily solar radiation as a potential candidate for development of PV energy systems in Afar region. Therefore, the PV system has the power to run an evaporative air conditioning system effectively. These findings indicate that photovoltaic energy system as most promising energy in the Afar region.
\end{abstract}

Keywords: Solar Energy, Solar Radiation Flux, Afar Region

\section{Introduction}

Ethiopia is sited in the Horn of Africa, located at $3-15^{\circ} \mathrm{N}$ latitude and $33-48^{\circ} \mathrm{E}$ longitude. Ethiopia covers an area of 1.13 million square kilometers. In terms of population, Ethiopia is household to over 110 million people, which makes it the second populated country in Africa next to Nigeria but $83 \%$ of which living in the rural areas World population prospects. In spite of Ethiopia has plentiful natural resources and huge energy resource in contradiction of that Ethiopia is experiencing serious energy deficiencies to encounter the growing energy demand, which is estimated to grow by approximately $30 \%$ annually [1]. The Ethiopia energy sector appearances the double challenges of inadequate access to present-day renewable energy alternative such as geothermal energy, solar energy and wind energy. Although Ethiopia has seen melodramatic economic progress in recent years, satisfying this development, the future will want theatrical growth of recent energy source with affordable cost [2].

Afar region is one of the nine governmental established regional states and it is the homeland of Afar people and located at $\left(11.45^{\circ} \mathrm{N}\right.$ and $\left.41^{\circ} \mathrm{E}\right)$ its capital city of Samara [2]. Its climate has luminous average range temperatures from $27^{\circ} \mathrm{C}$ to $50^{\circ} \mathrm{C}$ [3]. As consequence of airing and air conditioning system is the serious issues of the afar region to be appropriate situations for living conditions and workers $[4,5]$. Nowadays the afar region is energy sector relay on hydropower energy for the utility as well as basic living demands. Afar region is experiencing severe energy shortage and non-electrified locations, due to a number of problems such as high capital investment, low load factor, underprivileged voltage guideline and regular power supply disruptions. Access to energy provisions both profit generation events and the regional development program through civilizing education, dropping air effluence and guaranteeing atmosphere sustainability. The price to install and service the distribution of hydropower energy lines is significantly highly expensive and not cost 
effective in Afar region rural areas. In addition, there will be transmission losses to power supply consistency in rural grid $[6,7]$.

Furthermore, vast improvement of its efficiency from year to year shows that the photovoltaic PV energy can be an alternative primary energy source to replace the current operating system [8]. The goal of this research work is to assess the solar resource potential of Afar region in in compression with other regions and the whole country of Ethiopia. Additional objective is to provide a comprehensive overview of the solar energy capacity for pastoral community energy consumption, such as solar lighting, solar cooker, small DC applications in reasonable cost [9].

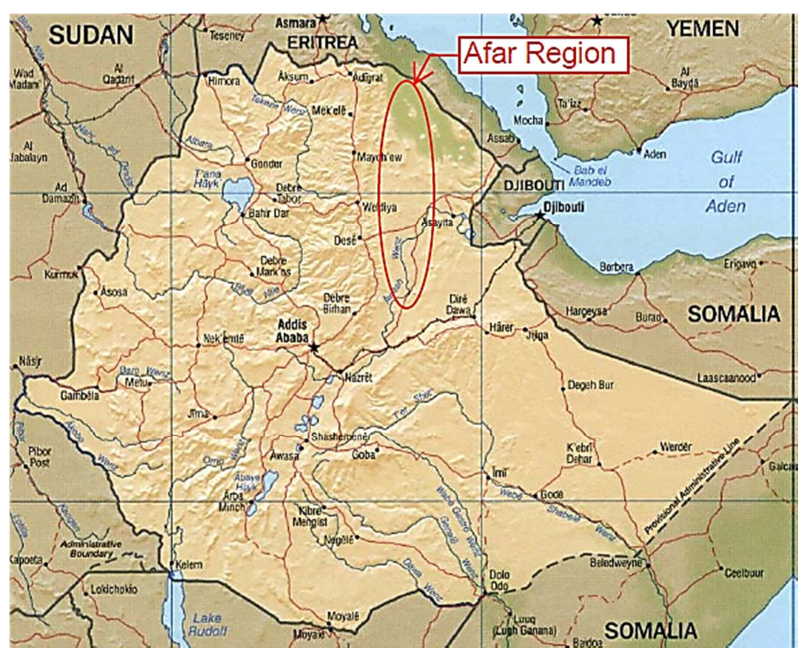

Figure 1. Afar region map [17].

\section{Current Energy Scenario in Ethiopia}

The major source of energy in Ethiopia is biomass, which financial statement for $91 \%$ of energy paid [10]. Petroleum supplies about $7 \%$ of whole prime energy and electricity used in only $2 \%$ of total energy use. The energy demand of Ethiopia is increasing rapidly due to the fast-developing nations on the continent. Ethiopia is gifted with numerous renewable energy resources such as hydropower $(45 \mathrm{GW})$, geothermal $(5 \mathrm{GW})$, wind $(10 \mathrm{GW})$ and solar flux ranges from $\left(4.5\right.$ to $7.5 \mathrm{kWh} / \mathrm{m}^{2} /$ day $)$ [11]. In spite of Ethiopia have abundant green energy potential, the country is suffering energy deficiencies as it scraps to meet the growing energy demand, approximately $30 \%$ annually [12]. The development of Ethiopia's energy sectors derived from Growth and Transformation Strategy, which redesign the country into a middle-income state by 2025 . The GTP I was reputed in 2010 and comprised a goal line of growing the Ethiopia energy capacity from $2 \mathrm{GW}$ to $8 \mathrm{GW}$.

The energy sector of Ethiopia continues to be subject to more than $85 \%$ of hydropower energy to meet growing demand, which is becoming less reliable as droughts intensify. According to current Ethiopia energy scenarios, there are four sectors which determine the energy needs such as in agriculture, industry, service and transport sector for electrification [9-11]. Most important alternative investments conserve energy, improve environmental sustainability, improve energy equity and improve the country's development indicators as shown in table 1.

Table 1. Energy demand from 2015 to 2037 in different sector.

\begin{tabular}{lllll}
\hline Years & AS/MW & IS/MW & SS/MW & TS /MW \\
\hline 2015 & 197 & 447 & 304 & 97 \\
2020 & 1123 & 1007 & 381 & 319 \\
2025 & 3342 & 2845 & 582 & 553 \\
2030 & 3556 & 3994 & 950 & 879 \\
2035 & 4756 & 4986 & 1498 & 1365 \\
2037 & 5219 & 7002 & 2624 & 1564 \\
\hline
\end{tabular}

AS: agriculture sector, IS: industry sector, SS: Service Sector, TS: transport sector

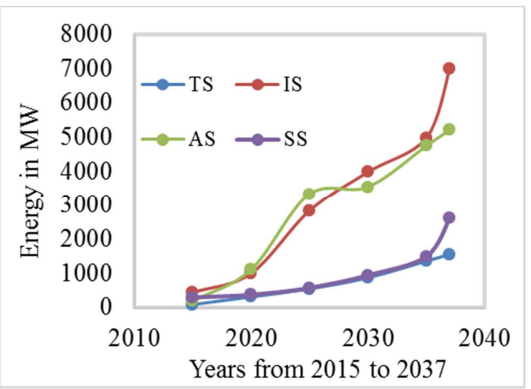

Figure 2. Plot of Energy demand forecast of different energy sector vs energy in $M W$.

The Ethiopian energy report predictable energy request in different sector from 2015 to 2037 by the Ethiopian Economic Plan [13, 14]. As different area energy needs as Agriculture Sector (197 to $5219 \mathrm{MW}$ ) it increases $25.67 \%$ increase, Industrial Sector (447 to $7002 \mathrm{MW}$ ) it increases $16.07 \%$, service sector (304 to 2624) it increases $8.7 \%$ and transport sector ( 97 to $1564 \mathrm{MW}$ ) it increases $16.4 \%$ in energy per time and power [15]. The Ethiopian Development and Transformation Proposal highlights the importance of energy efficiency and energy conservation as shown in figure 2 .

\section{Methods}

In this research Solar shortwave radiation transfer model is implanted in each of small-scale meteorological numerical models (WRF, MM5, etc.). In this model, solar shortwave radiation reaching upper bound on earth-atmosphere system, scattering and absorption by the cloudless atmosphere (molecule in air, water vapor, aerosol, etc.). On solar radiation travel path and loss of solar shortwave radiation due to cloud reflection and absorption are calculated successively, thus the solar radiation power of unit area can be worked out. Based on integration for diverse regions and times, solar powers and solar energy reserves in different regions can be concluded. This provides conditions for statistics and assessment solar energy resource $[16,17]$

\section{Results and Discussion}

\subsection{Ethiopia Solar Energy Potential}

According to various research reports of solar PV projects 
presents an extremely profitable opportunity for investors. The country's irradiation levels average around minimum range from $1858 \mathrm{Wh} / \mathrm{m}^{2} /$ month (in December) to 15,348 $\mathrm{Wh} / \mathrm{m}^{2} /$ month, (in April) and at maximum range increase from lower peak $207,232 \mathrm{Wh} / \mathrm{m}^{2} /$ month (in Fuberary) to highest peak $255,147 \mathrm{Wh} / \mathrm{m}^{2} /$ month (in May) as shown in figure 3 (table 2). In addition, in mean value and St. Dev the variability of solar radiation approximately uniform throughout the year as shown in figure 3 [18]. This information provides Ethiopia has gotten attention for solar energy investment and for the development of utility-scale PV plants. Based on the standard meteorological assessment of solar energy resources annual total solar radiation in any region of the country range from $1400 \mathrm{~kW} \cdot \mathrm{h} /\left(\mathrm{m}^{2} \cdot \mathrm{a}\right)$ to 1750 $\mathrm{kW} \cdot \mathrm{h} /\left(\mathrm{m}^{2} \cdot \mathrm{a}\right)$. When we analyse annual total solar energy distribution in four different periods of time as (1980 2009, 1980 1990, 1991 1999, and 2000 2009). As Ethiopia topographies high in the north from $8^{\circ} \mathrm{N}$ to $14^{\circ} \mathrm{N}$ and low in the south, especially, annual total solar radiation exceeds $2100 \mathrm{~kW} \cdot \mathrm{h} /\left(\mathrm{m}^{2} \cdot \mathrm{a}\right)$ in the central part of North Ethiopia as shown figure $4 \mathrm{a}$ in 1980 2009. In the second years interval as shown figure $4 \mathrm{~b}$ in $1980 \sim 1990$ total solar radiation distribution is similar as north from $8^{\circ} \mathrm{N}$ to $14^{\circ} \mathrm{N}$ but it is significantly different between the former period $[19,20]$.

Table 2. Temporal monthly radiation in Ethiopia.

\begin{tabular}{lllll}
\hline Month & Min & Max & Mean & St. Dev \\
\hline January & 1930 & 221,940 & 136,288 & 16,161 \\
Fuberary & 2148 & 207,232 & 138,439 & 13212 \\
March & 3646 & 236,328 & 170,906 & 12,501 \\
April & 15,348 & 238,981 & 172,893 & 11,899 \\
May & 6961 & 255,147 & 176,442 & 14,233 \\
June & 3,286 & 250,390 & 167,735 & 14,906 \\
July & 4,026 & 257,094 & 175,074 & 14,788 \\
August & 11,533 & 249,714 & 178,741 & 12,792 \\
September & 6,624 & 239,322 & 174,338 & 12,143 \\
October & 2,376 & 224,323 & 153,691 & 13,549 \\
November & 1912 & 216,207 & 135,489 & 15,351 \\
December & 1858 & 219,516 & 130,485 & 16,523 \\
\hline
\end{tabular}

In third period 1991 1999 GC solar radiation distribution is similar to $1980 \sim 1990 \mathrm{GC}$ period. In fourth period 2000 2009 GC, solar radiation fell in Central Ethiopia and West Ethiopia as shown figure 4d. Low-radiation zone was more obvious in the southern parts of central west Ethiopia. In spite of the reduction in radiation quantity of the high radiation zone, an area of such zone increased. In the southeast part, solar radiation of low-radiation zone increased, without obvious low-radiation zone.

The annual total solar energy distribution in four different periods of time shows that significantly higher solar radiation that the degree from $8^{\circ} \mathrm{N}$ in $14^{\circ} \mathrm{N}$. Therefore, geographically Afar region is located $11.45^{\circ} \mathrm{N}$ and $41^{\circ} \mathrm{E}$ and Average Annual Total Solar Radiation recoded at $8^{\circ} \mathrm{N}$ to $14^{\circ} \mathrm{N}$ and at $35^{\circ} \mathrm{E}$ to $42^{\circ} \mathrm{E}$ in four different times. This indicates that afar region has potato solar radiation

Figure 5 illustrates average annual total Solar Radiation, distribution in northern Ethiopia at interval of $4^{\circ} \mathrm{N}$ to $14^{\circ} \mathrm{N}$ in four different years as shown table 3 . As figure 5 shows that in four different -time interval years Solar Radiation, distribution increased in similar pattern [21].

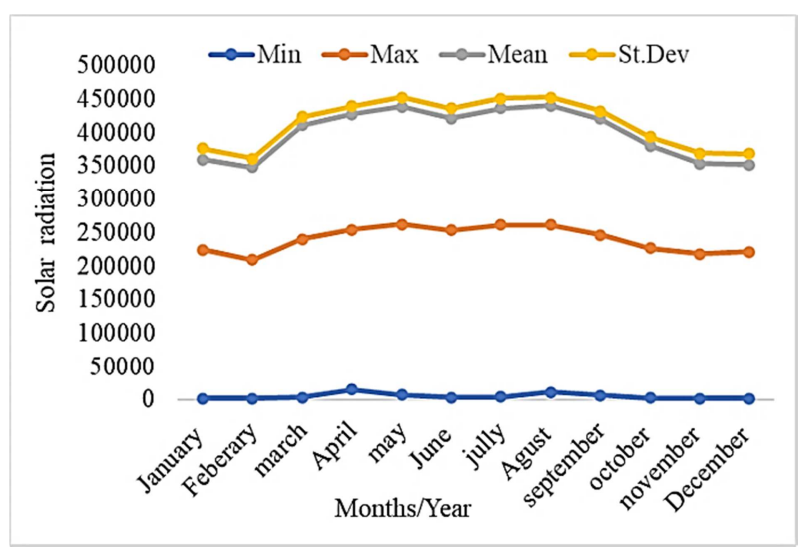

Figure 3. Monthly global solar radiation of Ethiopia.

Table 3. Average Annual Total Solar Radiation, distribution $\mathrm{kW} \cdot \mathrm{h} /(\mathrm{m} 2 \cdot \mathrm{a})$ ), (a) (1980 2009 GC) (b) 1980 1990 GC (c) 1990 1999 GC) (d) 2000 2009).

\begin{tabular}{lllll}
\hline Direction & a & b & c & d \\
\hline $4 \mathrm{~N}$ & 1500 & 1520 & 1500 & 1550 \\
$6 \mathrm{~N}$ & 1710 & 1720 & 1700 & 1690 \\
$8 \mathrm{~N}$ & 1830 & 1850 & 1800 & 1820 \\
$10 \mathrm{~N}$ & 2000 & 2010 & 2020 & 1970 \\
$14 \mathrm{~N}$ & 2130 & 2150 & 2160 & 2110 \\
\hline
\end{tabular}

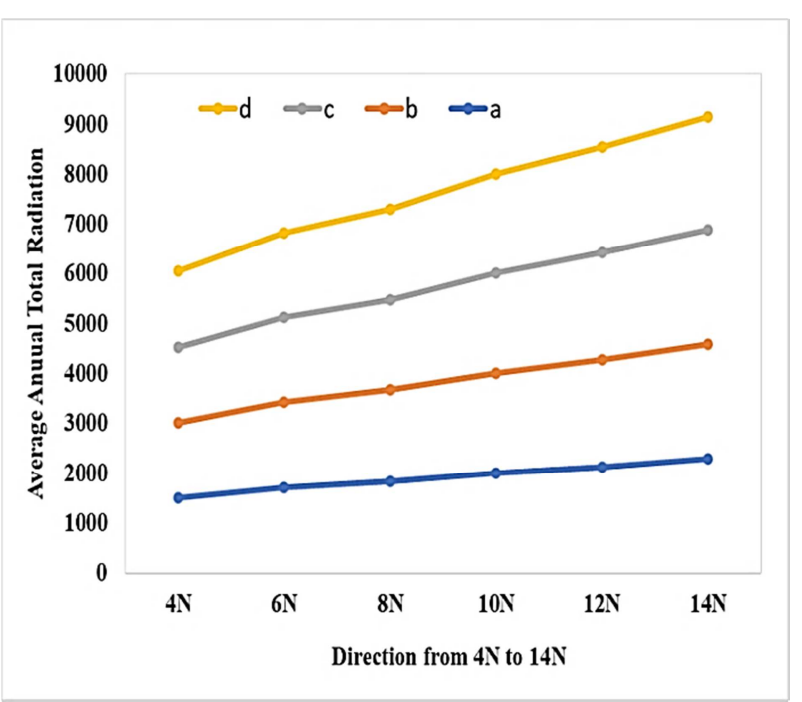

Figure 4. Average Annual Total Solar Radiation, distribution $\mathrm{kW} \cdot \mathrm{h} /\left(\mathrm{m}^{2} \cdot \mathrm{a}\right)$, in different degree of north direction.

\subsection{Afar Region Solar Energy Potential}

Solar irradiation on the earth's surface is the fundamental energy for various biological, physical, and chemical processes. It is a renewable energy resource that has been used by humanity without age limit. Solar radiation data on the surface of the earth is significant for various applications in meteorology, agricultural sciences, engineering and in research in different fields of natural sciences as well as at the diversity of applications may include: solar heating system design, solar power generation. Ethiopia has plentiful solar energy resources. According to study solar energy potential on 
a regional basis, the yearly average radiation ranges from values as low in western Ethiopia in the areas in (Gambella regional, state) to values as high at northern Ethiopia around in (Tigray regional state and in Afar regional state) [3]. The solar and wind energy resource assessment (SWERA) reports show that, solar energy resource richest regions in Ethiopia are mainly centralized in the Afar State in the northeast, the desert region in Somali State in the southeast and some western and southern regions. Mid North region of Ethiopia is relatively weaker in solar energy resources. Average solar radiation power and average annual total solar energy of unit area are higher in Tigray $\left(246.48 \mathrm{~W} / \mathrm{m}^{2}\right)$, Amhara $\left(240.34 \mathrm{~W} / \mathrm{m}^{2}\right)$ and the Afar $\left(239.9 \mathrm{~W} / \mathrm{m}^{2}\right)$ respectively. For example, solar radiation power density in Tigray exceeds, solar radiation power density of Afar and Amhara regions

Table 4. Solar Energy Resource in Different Regions of Ethiopia.

\begin{tabular}{|c|c|c|c|c|c|}
\hline Country /state & Area $\left(1,000\right.$ km$\left.^{2}\right)$ & Av. S. flux $\left(W / m^{2}\right)$ & T R P (TW) & Av. Ap $\left(M W \cdot h /\left(m^{2} \cdot a\right)\right)$ & An. Anl TR (PW·h/a) \\
\hline Afar & 94.1 & 239.9 & 22.57 & 2.102 & 198 \\
\hline Amhara & 155 & 240.34 & 37.26 & 2.105 & 326 \\
\hline Benshagul & 49.5 & 232.52 & 11.5 & 2.037 & 101 \\
\hline Oromiya & 320 & 223.96 & 71.66 & 1.962 & 628 \\
\hline SNNP & 109.9 & 226.65 & 24.91 & 1.986 & 218 \\
\hline Somali & 300.3 & 217.19 & 65.21 & 1.903 & 571 \\
\hline Ethiopia & 1,104 & 227.42 & 250.98 & 1.992 & 2199 \\
\hline
\end{tabular}

In comparison to other regions and total solar radiation, afar region cover third rank next to Tiger and Amara region. However, to consider total solar energy in different regions, it is necessary to consider areas of different regions. For this, Oromiya, Somali and Amhara are of advantage. In terms of average annual flux density Afar $\left(2.102 \mathrm{MW} \cdot \mathrm{h} /\left(\mathrm{m}^{2} \cdot \mathrm{a}\right)\right)$, Amhara $\left(2.105 \mathrm{MW} \cdot \mathrm{h} /\left(\mathrm{m}^{2} \cdot \mathrm{a}\right)\right)$, Tigray $\left(2.159 \mathrm{MW} \cdot \mathrm{h} /\left(\mathrm{m}^{2} \cdot \mathrm{a}\right)\right)$ exceeds the average annual flux density of the whole country as shown in (Table 4). Solar flux in Different Regions of Ethiopia. It illustrates Solar flux in Afar region $\left(239.9 \mathrm{~W} / \mathrm{m}^{2}\right)$ per $\left(1,000 \mathrm{~km}^{2}\right)$ which exceed other regions next to Tigray region $\left(246.48 \mathrm{~W} / \mathrm{m}^{2}\right)\left(50.2 \mathrm{~km}^{2}\right)$.

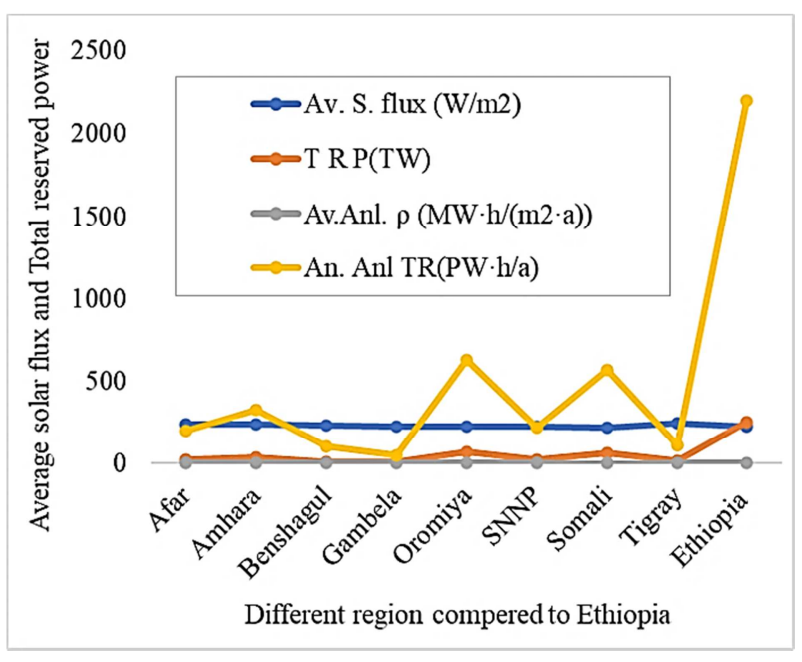

Figure 5. Solar energy potential in different region in Ethiopia [17].

\section{Conclusion}

The study indicates that the afar region being exceptional solar potential with significant AV. Solar flux of $239.9 \mathrm{~W} / \mathrm{m} 2$ ), AV. Annual. Density $2.102 \mathrm{MW} \cdot \mathrm{h} / \mathrm{m}^{2} \cdot \mathrm{a}$, therefore the afar region is the prospective candidate for the development of $\mathrm{PV}$ power systems. Therefore, the PV system has the power to run an evaporative air conditioning system effectively. In order to save the energy bill and initial capital cost of this air conditioning system, the cooling load of the considered building has been estimated. The solar energy alternative has significant benefit to pastoral community and provide as Afar, more secure and healthier environment for women and children. The PV systems have been the main pillar of solar energy in Afar region so far, it is expected that these types of systems could bring more immediate solutions for inhabitants without access to common energy source in Afar region hydroelectric energy. Therefore, Solar energy can be the best alternative for daily life consumption, such as solar lighting, for solar cooker, small DC applications and for air conditioning applications. This shows, a great potential of Solar (PV) power system in future as one of renewable energy technology alternatives for hydroelectric power generation.

\section{References}

[1] World population prospects (2019 Revision).

[2] Solar Energy Resources, Technical Report 3, CESEN 1986.

[3] Ahmed, D., Sharif, A. R. H. "Design and development of photovoltaic power system for greenhouse cooling". A. J. of Applied Science 2007, 4/6: 386-389.

[4] Arora. S. P., "A text book of building construction including Engineering materials, for engineering students, fifth edition", 2005. 1-21.

[5] Tamrat. B., "Comparative Analysis of Feasibility of Solar PV, Wind and Micro Hydro Power Generation for Rural Electrification in the selected sites of Ethiopia. Master thesis, Addis Ababa University", 2007.

[6] Bogale1. B., Alemayehu, A., "Optimal Design of a Standalone Photovoltaic Power Supply System for Air Conditioning Application at Samara University as an Alternative to Diesel Generator Source", Sci. Technol. Arts Res. J., 2012, 1/2: 65-71, www.starjournal.org. 
[7] Hunt L. A., Kucharb L., Swanton C. J. Agricultural and Forest Meteorology; 1998 91: 293-300.

[8] A. Dalelo "Natural Resource Degradation in Ethiopia: Assessment of Students' Awareness and Views". Flensburger Regional Studien, Band, Flensburg 2001.

[9] Badescu. V., "Modelling Solar Radiation at the Earth's Surface: Recent Advances", Berlin Heidelberg, Springer-Verlag 2008M. Young, The Technical Writer's Handbook. Mill Valley, CA: University Science, 198.

[10] Gudina T. T., Sanderine N., "Alternative energy supply system to a rural village in Ethiopia" Energy, Sustainability and Society (2017) 7: 33 .

[11] Senshaw. D. A., "Modelling and analaysis of long-term energy scenarios for sustainable strategies of Ethiopia". PhD Dissertation. University Flensburg. 2014.

[12] Samuel T., Getachew B., "International Journal of Energy and Power Engineering” 2014; 3 (6): 331-340.

[13] Tilahun N., Wondwossen B. Feyisa B. Edessa D, "Feasibility study for power generation using off- grid energy system from micro hydro-PV-diesel generator-battery for rural area of Ethiopia: The case of Melkey Hera village, Western Ethiopia" AIMS Energy, 5 (4): 667-690. DOI: 10.3934/energy.2017.4.667

[14] Tesema, S. Bekele, G., "Resource Assessment and Optimization Study of Efficient Type Hybrid Power System for Electrification of Rural District in Ethiopia". International Journal of Energy and Power Engineering. 3, 6, 2014, 331-340.
[15] Dawit H. M "Ethiopian Energy Systems: Potentials, Opportunities and Sustainable Utilization" Uppsala, Sweden, September 2010

[16] Baseem K., Pawan S., "The Current and Future States of Ethiopia's Energy Sector and Potential for Green Energy: A Comprehensive Study" International Journal of Engineering Research in Africa ISSN: 2017, 33, 115-139.

[17] Jiangtao. M., Lushi, X., Kai, Z., Shuhua, G. Xiaojun, L. Chengzhi, W., Bo. Z., "Master Plan Report of Wind and Solar Energy in the Federal Democratic Republic of Ethiopia" 2012, 73-81.

[18] Bob V. Z., Agnese B., Francesco D. L., "Prospects for hydropower in Ethiopia: An energy-water nexus analysis" Energy Strategy Reviews 19 (2018) 19e30.

[19] Md A. H. M., Elizabeth B., Claudia R., Dawit M., Mark R., "Ethiopian energy status and demand scenarios: Prospects to improve energy efficiency and mitigate GHG emissions" Energy 149 (2018) 161-172.

[20] Mengistu. M. G., Simane,. B., Eshete,. G.,. Workneh. T. S., “A review on Bioge technology and its contributions to sustainable rural livelihood in Ethiopia”. Renew Sustain Energy Rev 2015; 48: 306e16.

[21] Muneer. T., "Solar Radiation and Daylight Models, 2nd ed" Elsevier Butterworth- Heinemann 2004.

[22] https://globalsolaratlas.info.

[23] "Ministry of Water Irrigation and Electricity, Materials, System Design and Applications" 15 2018, AASTU and ICTP Addis Ababa. 